\title{
Randomized controlled trial of deutetrabenazine for tardive dyskinesia
}

\author{
The ARM-TD study \\ OPEN $\approx$ 回全
}

Hubert H. Fernandez, MD

Stewart A. Factor, DO

Robert A. Hauser, MD, MBA

Joohi Jimenez-Shahed, MD

William G. Ondo, MD

L. Fredrik Jarskog, MD

Herbert Y. Meltzer, MD

Scott W. Woods, MD

Danny Bega, MD, MSCI

Mark S. LeDoux, MD, $\mathrm{PhD}$

David R. Shprecher, DO, MS

Charles Davis, PhD

Mat D. Davis, PhD

David Stamler, MD

Karen E. Anderson, MD

Correspondence to

Dr. Fernandez:

fernanh@ccf.org

\section{ABSTRACT}

Objective: To determine the efficacy and safety of deutetrabenazine as a treatment for tardive dyskinesia (TD).

Methods: One hundred seventeen patients with moderate to severe TD received deutetrabenazine or placebo in this randomized, double-blind, multicenter trial. Eligibility criteria included an Abnormal Involuntary Movement Scale (AIMS) score of $\geq 6$ assessed by blinded central video rating, stable psychiatric illness, and stable psychoactive medication treatment. Primary endpoint was the change in AIMS score from baseline to week 12. Secondary endpoints included treatment success at week 12 on the Clinical Global Impression of Change (CGIC) and Patient Global Impression of Change.

Results: For the primary endpoint, deutetrabenazine significantly reduced AIMS scores from baseline to week 12 vs placebo (least-squares mean [standard error] -3.0 [0.45] vs -1.6 [0.46], $p=0.019)$. Treatment success on CGIC (48.2\% vs $40.4 \%)$ favored deutetrabenazine but was not significant. Deutetrabenazine and placebo groups showed low rates of psychiatric adverse events: anxiety (3.4\% vs $6.8 \%)$, depressed mood/depression (1.7\% vs $1.7 \%)$, and suicidal ideation (0\% vs $1.7 \%$, respectively). In addition, no worsening in parkinsonism, as measured by the Unified Parkinson's Disease Rating Scale motor subscale, was noted from baseline to week 12 in either group.

Conclusions: In patients with TD, deutetrabenazine was well tolerated and significantly reduced abnormal movements.

Classification of evidence: This study provides Class I evidence that in patients with TD, deutetrabenazine reduces AIMS scores. Neurology ${ }^{\circledR}$ 2017;88:2003-2010

\section{GLOSSARY}

$\mathbf{A E}=$ adverse event; $\mathbf{A I M S}=$ Abnormal Involuntary Movement Scale; $\mathbf{A R M - T D}=$ Aim to Reduce Movements in Tardive Dyskinesia; CGIC = Clinical Global Impression of Change; $\mathbf{C l}=$ confidence interval; DRA = dopamine receptor antagonist; First-HD = First Time Use of SD-809 in Huntington Disease; HADS = Hospital Anxiety and Depression Scale; HD = Huntington disease; $\mathbf{L S}=$ least-squares; $\mathbf{m C D Q}-\mathbf{2 4}=$ modified Craniocervical Dystonia Questionnaire; $\mathbf{m I T T}=$ modified intent-to-treat; PGIC = Patient Global Impression of Change; $\mathbf{Q T c F}=\mathrm{QT}$ interval corrected with the Fridericia formula; $\mathbf{S E}=$ standard error; TD = tardive dyskinesia; VMAT2 = vesicular monoamine transporter 2

Tardive dyskinesia (TD) is a movement disorder resulting from exposure to dopamine receptor antagonists (DRAs), including typical and atypical antipsychotics, antiemetics, and metoclopramide. ${ }^{1-3}$ TD can affect any part of the body and be debilitating. ${ }^{1,4}$ Approximately $20 \%$ to $50 \%$ of patients receiving antipsychotics develop TD. ${ }^{5}$ The pathophysiology of TD is unknown, but upregulation and sensitization of $\mathrm{D} 2$ receptors after prolonged blockade may be contributory., ${ }^{5,6}$ Continued DRA use may worsen symptoms, ${ }^{1,6}$ while dose reduction can increase the risk of

From the Cleveland Clinic (H.H.F.), Center for Neurological Restoration, Cleveland, OH; Emory University (S.A.F.), Atlanta, GA; University of South Florida Parkinson's Disease and Movement Disorders Center (R.A.H.), Tampa, FL; Baylor College of Medicine (J.J.-S.), Houston, TX; Methodist Neurological Institute (W.G.O.), Houston, TX; University of North Carolina School of Medicine (L.F.J.), Chapel Hill, NC; Northwestern University Feinberg School of Medicine (H.Y.M., D.B.), Chicago, IL; Yale School of Medicine (S.W.W.), New Haven, CT; University of Tennessee Health Science Center (M.S.L.), Memphis, TN; University of Utah Health Care (D.R.S.), Salt Lake City, UT; Banner Sun Health Research Institute (D.R.S.), Sun City, AZ; CSD Biostatistics (C.D.), Tucson, AZ; Teva Pharmaceutical Industries (M.D.D.), Frazer, PA; Teva Pharmaceuticals (D.S.), La Jolla, CA; and Georgetown University (K.E.A.), Washington, DC.

Go to Neurology.org for full disclosures. Funding information and disclosures deemed relevant by the authors, if any, are provided at the end of the article. The Article Processing Charge was funded by Teva Pharmaceutical Industries.

This is an open access article distributed under the terms of the Creative Commons Attribution-NonCommercial-NoDerivatives License 4.0 (CC BY-NC-ND), which permits downloading and sharing the work provided it is properly cited. The work cannot be changed in any way or used commercially without permission from the journal. 
psychiatric relapse or acutely worsen TD. ${ }^{7-10}$ In $>80 \%$ of patients, TD appears irreversible, even after the causative agent is discontinued. ${ }^{11}$ There are currently no US Food and Drug Administration-approved treatments for TD. ${ }^{12}$ Although some off-label treatments have been studied for the management of $\mathrm{TD},{ }^{8}$ a significant unmet need remains for a tolerable and efficacious treatment option that allows the continuation of concomitant DRA use for underlying comorbidities.

Tetrabenazine is a vesicular monoamine transporter 2 (VMAT2) inhibitor that modulates synaptic dopamine. ${ }^{13}$ Tetrabenazine is rapidly and extensively converted in the liver to alpha and beta active metabolites, which are potent and selective inhibitors of VMAT2.

These active metabolites have short halflives that necessitate frequent dosing and result in large plasma fluctuations that are thought to contribute to the poor tolerability often observed. ${ }^{14,15}$ Conventional tetrabenazineassociated neuropsychiatric adverse events (AEs), including somnolence, depression, insomnia, akathisia, and parkinsonism, may limit its use. ${ }^{13}$

Deutetrabenazine is a novel, highly selective VMAT2 inhibitor containing deuterium, a naturally occurring, nontoxic form of hydrogen. ${ }^{16}$ Incorporation of deuterium attenuates metabolism, leading to decreased plasma fluctuations compared with conventional tetrabenazine, ${ }^{17,18}$ with potential to reduce AEs associated with peak concentrations. For example, deutetrabenazine significantly decreased chorea, improved overall motor function, and was well tolerated, with low rates of neuropsychiatric symptoms in patients with Huntington disease (HD), ${ }^{19}$ a population with high psychiatric comorbidity. ${ }^{20}$ This study evaluates the efficacy, safety, and tolerability of deutetrabenazine for the treatment of TD.

METHODS Primary research question. Is deutetrabenazine effective at reducing the severity of abnormal involuntary movements of TD as measured using the Abnormal Involuntary Movement Scale (AIMS) score? This study provides Class I evidence that in patients with TD, deutetrabenazine reduces AIMS scores.

Standard protocol approvals, registrations, and patient consents. This phase II/III trial is registered at ClinicalTrials.gov (NCT02195700). Written approval of the study protocol was obtained from the independent ethics committee at each site. Informed consent was secured for each patient. This study was conducted from June 2014 to May 2015.

Patient population. Participants had a TD diagnosis for $\geq 3$ months before screening and a history of DRA treatment for $\geq 3$ months ( $\geq 1$ month if age $\geq 60$ years). Patients were required to have investigator-assessed total AIMS motor score $\geq 6$ (examination of items 1-7) at both screening and baseline, verified by a blinded central rater at screening. For logistic reasons, the video of the AIMS motor score at baseline could not be assessed by blinded central rating until after randomization. Psychoactive medication use, including antipsychotics, was allowed if stable for $\geq 30$ days before screening (antidepressants $\geq 45$ days).

Treatment with tetrabenazine, reserpine, $\alpha$-methyl-p-tyrosine, strong anticholinergic medications, metoclopramide, dopamine agonists, levodopa, and/or stimulants within 30 days of screening or baseline was exclusionary, as was treatment with botulinum toxin within 3 months of screening. Other exclusions included presence of a neurologic condition that could confound TD assessments, serious untreated or undertreated psychiatric illness, or unstable medical illness. Patients with history of or active suicidal ideation or behavior within 6 months of screening or score $\geq 11$ on the depression subscale of the Hospital Anxiety and Depression Scale (HADS) were excluded. A corrected QT interval with the Fridericia formula (QTcF) of $>450$ milliseconds in men or $>460$ milliseconds in women on 12-lead ECG at screening was also exclusionary.

Study design. This was a 12 -week, randomized, double-blind, parallel-group study conducted at 46 sites in the United States and Europe. Patients were centrally randomized 1:1 to receive deutetrabenazine or matching placebo and stratified by use of DRA at baseline (currently taking vs not currently taking a DRA). Randomization and stratification were performed through an Interactive Technology Response System. Both patients and site investigators remained blinded to treatment assignment throughout the study.

After randomization, study drug was started at $12 \mathrm{mg} / \mathrm{d}(6 \mathrm{mg}$ twice daily) and titrated weekly by $6 \mathrm{mg} / \mathrm{d}$, if required, for up to 6 weeks until adequate dyskinesia control was achieved, a significant $\mathrm{AE}$ occurred, or the maximal allowable dose $(48 \mathrm{mg} / \mathrm{d})$ was reached; this was followed by maintenance ( 6 weeks) and a 1 week washout. The investigator, in consultation with the patient and caregiver (if applicable), determined the optimal dose for dyskinesia control. In patients receiving a strong CYP2D 6 inhibitor, the maximum allowed dose of deutetrabenazine was $36 \mathrm{mg} / \mathrm{d}$. Clinic visits and AIMS evaluations were performed at weeks 2, 4, $6,9,12$, and 13 . Telephone consultations occurred at weeks 1,3 , 5 , and 7 .

Efficacy assessments. The primary endpoint was change in AIMS score from baseline to week 12 as assessed by 2 blinded central video raters who were movement disorders experts. For each of the 7 body regions, a consensus AIMS rating was reached. Video recordings were blinded with respect to treatment, visit number, investigation site, and recording date. All videos for a single patient were reviewed by both raters in a single session.

Secondary endpoints included proportion of patients who experienced treatment success at week 12 on the Clinical Global Impression of Change (CGIC) and Patient Global Impression of Change (PGIC), 7-point Likert scales ranging from very much worse to very much improved. CGIC assessment occurred at weeks 2, 4, 6, 9, and 12. PGIC assessment occurred weeks 4, 6, 9, and 12. Treatment success on the CGIC and PGIC was defined as much improved or very much improved at week 12 . 
The change from baseline in modified Craniocervical Dystonia Questionnaire (mCDQ-24) score was also measured. The mCDQ-24 contains domains that are relevant to TD, such as stigma, emotional well-being, pain, activities of daily living, and social/family life, thereby enabling the evaluation of the effect and significance of TD on patients' quality of life.

Because the baseline visit video could not be assessed by central raters before randomization, some of the enrolled patients had an AIMS motor score $<6$ when assessed by the central raters; these patients were enrolled in the study on the basis of an AIMS score of $\geq 6$ at baseline, as assessed by the local site rater. Therefore, a post hoc analysis of patients with centrally read AIMS motor scores $\geq 6$ at both screening and baseline was performed. Other efficacy endpoints such as CGIC, PGIC, and mCDQ-24 were also analyzed.

Safety assessments. AEs were monitored throughout the study and are reported after randomization. Dose reductions, suspensions, and withdrawals due to AEs were also monitored. ECG readings were measured at baseline and weeks 2 and 12; additional readings occurred at weeks 4,6 , and 9 for patients receiving medications that potentially prolong the QT interval. Assessment of Unified Parkinson's Disease Rating Scale motor subscale, Barnes Akathisia Rating Scale, HADS, Columbia Suicide Severity Rating Scale, and Epworth Sleepiness Scale scores occurred at baseline and all clinic visits. The Montreal Cognitive Assessment scale was performed at baseline and maintenance. Dosing decisions were made without knowledge of CYP2D6 metabolism status.

Statistical analysis. Efficacy analyses were conducted in the modified intent-to-treat (mITT) population, which included all randomized patients who received study drug and had at least one postbaseline AIMS assessment. The safety population included patients who received at least one dose of study drug. The primary analysis of change in AIMS score from baseline was conducted with a linear mixed model for repeated measurements that included fixed effects for treatment group, time point, treatment group by time point interaction, and concomitant DRA use at baseline. Baseline AIMS score was included as a covariate, and the unstructured covariance model was used. The primary efficacy analysis compared treatment groups at week 12 with the use of a 2 -sided test at the $5 \%$ significance level. Secondary endpoints, defined as proportions of patients with treatment success (e.g., CGIC and PGIC), were compared between treatment groups with the Pearson $\chi^{2}$ test. Change in mCDQ-24 score from baseline to week 12 was analyzed with an analysis of covariance model with treatment group and concomitant DRA use at baseline as factors, and with baseline mCDQ-24 score included as a covariate.

Sample size. A 2-sided test at 5\% significance was applied and assumed an SD of 4.1 for the change from baseline to week 12 in AIMS score. Approximately 90 patients provided $90 \%$ power to detect a treatment difference of 2.8 units in the AIMS and $80 \%$ power to detect a treatment difference of 2.4 units.

RESULTS Patient baseline characteristics and disposition. A total of 117 patients with TD were randomized to receive deutetrabenazine $(\mathrm{n}=58)$ or placebo $(n=59)$. A comparable proportion of patients completed the study in both groups (figure 1). Both groups had similar demographics and

Figure 1 Flow of study patients

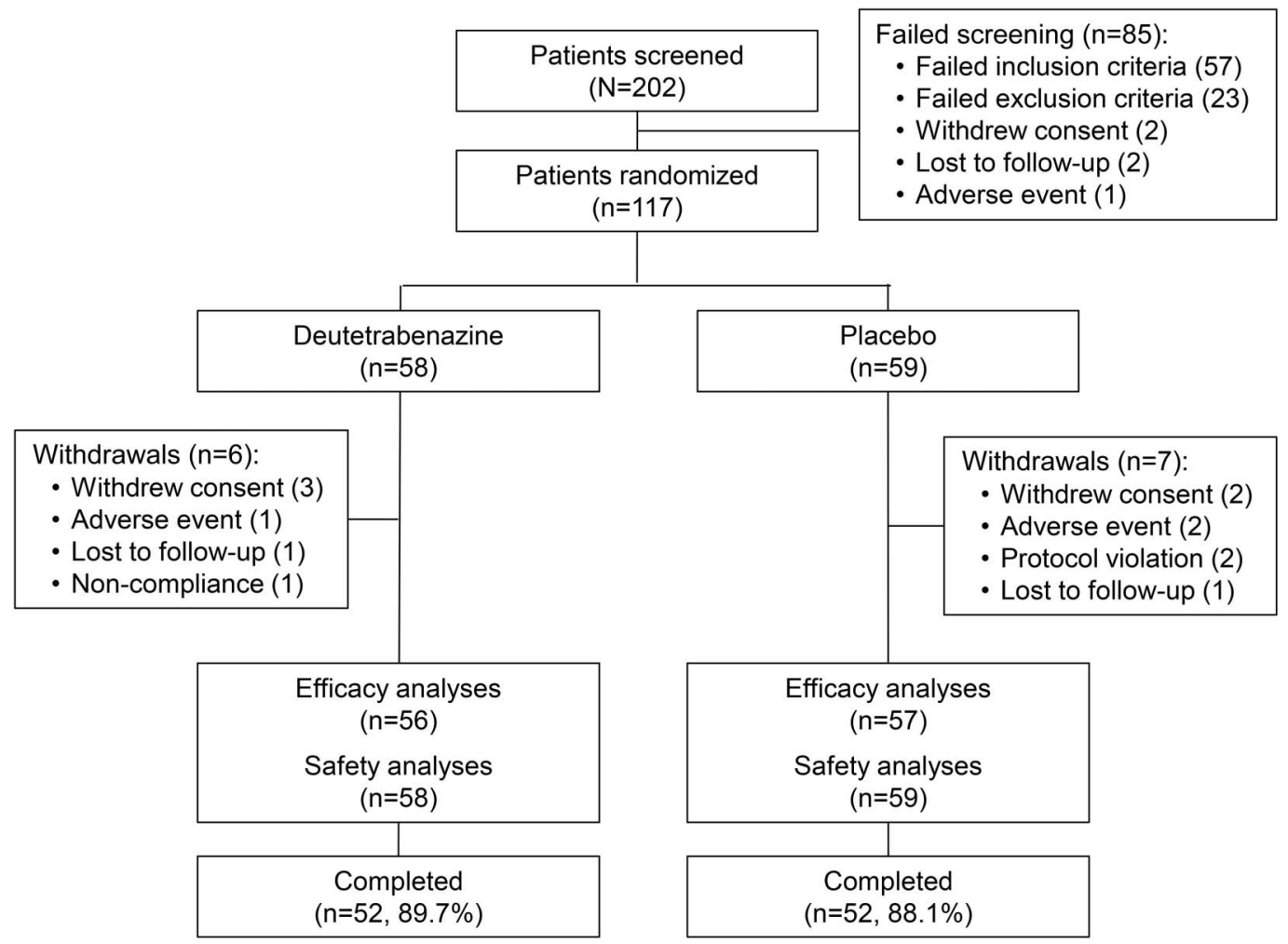

After screening for eligibility, 117 patients were randomized to receive deutetrabenazine or placebo. A total of $89.7 \%$ and $88.1 \%$ of patients completed 12 weeks of treatment with deutetrabenazine or placebo, respectively. 
baseline characteristics (table 1). Approximately 70\% of the population had an underlying diagnosis of schizophrenia or schizoaffective disorder (table 1); $23.1 \%$ had bipolar disorder; and $25.6 \%$ had depression. The majority of patients $(80.3 \%)$ were being

\section{Table 1 Patient baseline characteristics by treatment group}

\begin{tabular}{|c|c|c|c|}
\hline & $\begin{array}{l}\text { Deutetrabenazine } \\
(\mathrm{n}=58)\end{array}$ & $\begin{array}{l}\text { Placebo } \\
(\mathrm{n}=59)\end{array}$ & $\begin{array}{l}\text { All } \\
(n=117)\end{array}$ \\
\hline \multicolumn{4}{|l|}{ Patient demographics } \\
\hline Age (SD), y & $55.9(9.8)$ & $53.3(10.6)$ & $54.6(10.3)$ \\
\hline Female, n (\%) & $29(50.0)$ & 32 (54.2) & $61(52.1)$ \\
\hline Male, n (\%) & $29(50.0)$ & $27(45.8)$ & $56(47.9)$ \\
\hline White, n (\%) & 37 (63.8) & $44(74.6)$ & $81(69.2)$ \\
\hline \multicolumn{4}{|l|}{ Patient clinical characteristics } \\
\hline Weight (SD), kg & $86.9(24.1)$ & $85.0(21.0)$ & $85.9(22.5)$ \\
\hline Duration of TD, mo & $72.6(81.7)$ & $76.8(82.1)$ & 74.7 (81.5) \\
\hline DRA use at baseline, $n(\%)$ & $45(77.6)$ & $49(83.1)$ & 94 (80.3) \\
\hline \multicolumn{4}{|l|}{$\begin{array}{l}\text { Most common antipsychotics } \\
\text { used at baseline, } n(\%)\end{array}$} \\
\hline Quetiapine & $14(24.1)$ & $18(30.5)$ & $32(27.4)$ \\
\hline Risperidone & 9 (15.5) & 7 (11.9) & $16(13.7)$ \\
\hline Olanzapine & $8(13.8)$ & $5(8.5)$ & $13(11.1)$ \\
\hline \multicolumn{4}{|l|}{$\begin{array}{l}\text { Most common antidepressants } \\
\text { used at baseline, } n(\%)\end{array}$} \\
\hline Trazodone & 9 (15.5) & $10(16.9)$ & 19 (16.2) \\
\hline Bupropion & $5(8.6)$ & 6 (10.2) & $11(9.4)$ \\
\hline Sertraline & $6(10.3)$ & $4(6.8)$ & $10(8.5)$ \\
\hline Citalopram & $5(8.6)$ & $5(8.5)$ & $10(8.5)$ \\
\hline \multicolumn{4}{|l|}{$\begin{array}{l}\text { Most common anxiolytics } \\
\text { used at baseline, } n(\%)\end{array}$} \\
\hline Hydroxyzine & $5(8.6)$ & 6 (10.2) & $11(9.4)$ \\
\hline Alprazolam & $4(6.9)$ & $4(6.8)$ & $8(6.8)$ \\
\hline Buspirone & $1(1.7)$ & $2(3.4)$ & $3(2.6)$ \\
\hline Diazepam & $1(1.7)$ & $2(3.4)$ & $3(2.6)$ \\
\hline $\begin{array}{l}\text { Psychiatric disorder comorbidity, } \\
\text { n (\%) }\end{array}$ & 57 (98.3) & $58(98.3)$ & 115 (98.3) \\
\hline Schizophrenia ${ }^{a}$ & $29(50.0)$ & 29 (49.2) & $58(49.6)$ \\
\hline Schizoaffective disorder ${ }^{b}$ & $11(19.0)$ & 11 (18.6) & $22(18.8)$ \\
\hline Bipolar disorder $^{\mathrm{C}}$ & $12(20.7)$ & $15(25.4)$ & $27(23.1)$ \\
\hline Depression & 17 (29.3) & $13(22.0)$ & $30(25.6)$ \\
\hline AIMS score, items 1-7 (SD) & $9.6(4.1)$ & $9.6(3.8)$ & $9.6(3.9)$ \\
\hline AIMS score $\geq 6, n(\%)$ & $48(82.8)$ & $49(83.1)$ & $97(82.9)$ \\
\hline Total mCDQ-24 score (SD) & $38.4(20.4)$ & 39.7 (18.2) & 39.1 (19.3) \\
\hline Total UPDRS score (SD) & $9.5(9.8)$ & $10.2(8.7)$ & $9.9(9.2)$ \\
\hline
\end{tabular}

Abbreviations: AIMS $=$ Abnormal Involuntary Movement Scale (maximum total score $=28$ ); DRA = dopamine receptor agonist; $\mathrm{mCDQ}-24$ = Modified Craniocervical Dystonia Questionnaire (maximum total score $=96$ ); TD = tardive dyskinesia; UPDRS = Unified Parkinson's Disease Rating Scale motor assessment (maximum total score $=56$ ).

${ }^{a}$ Includes schizophrenia, schizophrenia paranoid type, and schizophrenia residual type.

${ }^{b}$ Includes schizoaffective disorder and schizoaffective disorder depressive type.

${ }^{\mathrm{c}}$ Includes bipolar disorder, bipolar I disorder, and bipolar II disorder. treated with a DRA at baseline and continued treatment throughout the study.

Dose. At the end of the titration period, the mean (SD) total daily dose was $38.8(7.92) \mathrm{mg} / \mathrm{d}$. The mean $[\mathrm{SD}]$ dose remained stable until the end of the treatment period $(38.3[7.97] \mathrm{mg} / \mathrm{d})$.

Efficacy assessments. For the primary endpoint, deutetrabenazine significantly reduced AIMS scores from baseline to week 12 compared with placebo (least-squares [LS] mean [standard error (SE)]: $-3.0[0.45]$ vs $-1.6[0.46], p=0.019$; treatment difference $-1.4[0.60], 95 \%$ confidence interval [CI] -2.6 to -0.2 ) (figure 2). Improvement in AIMS score was different between the deutetrabenazine and placebo groups by week 4 with a treatment effect of $-1.5(95 \% \mathrm{CI}-2.6$ to $-0.4, p=$ 0.007).

While the percentage of patients who achieved treatment success on the CGIC ( $48.2 \%$ vs $40.4 \%$ ) and PGIC (42.9\% vs $29.8 \%)$ favored deutetrabenazine, these differences were not statistically significant. Similarly, deutetrabenazine-treated patients had a greater LS mean $[S E]$ reduction from baseline to week 12 in the mCDQ-24 score than placebo $(-11.1[2.14]$ vs $-8.3[2.31])$, but the difference was not statistically significant.

Of the 113 patients in the mITT population, 97 patients $(85.8 \%)$ had a centrally read AIMS score $\geq 6$ at both screening and baseline. Because this subgroup represents the intended population for the study, a post hoc analysis was performed on the primary and key secondary endpoints. Similar to the overall population, for the AIMS, deutetrabenazine-treated patients had a greater decrease in LS mean [SE] scores compared with placebo $(3.4[0.48]$ vs $1.9[0.51], p=0.027$; treatment difference -1.5 [0.67], 95\% CI -2.8 to -0.2 ) (figure 3). In the same subpopulation, the difference in the percentage of patients who were classified as a treatment success on the basis of the CGIC widened between the deutetrabenazine vs placebo arms compared with the entire mITT cohort (25 [52.1\%] vs 17 [34.7\%], $p=0.084$; treatment difference $17.4 \%, 95 \% \mathrm{CI}-2.2 \%$ to $35.3 \%)$. The treatment difference in this subpopulation was $17.4 \%$ compared with $7.9 \%$ in the mITT cohort. Compared with placebo, a greater percentage of deutetrabenazine-treated patients in this subpopulation had treatment success based on the PGIC ( $45.8 \%$ vs $28.6 \%)$. Patients in the deutetrabenazine group also had a greater LS mean [SE] reduction from baseline to week 12 in the mCDQ-24 total score $(-12.2[2.21]$ vs $-6.6[2.39])$. Similar to the mITT population, these results were not statistically significant. 
Figure $2 \quad$ Mean change in AIMS score

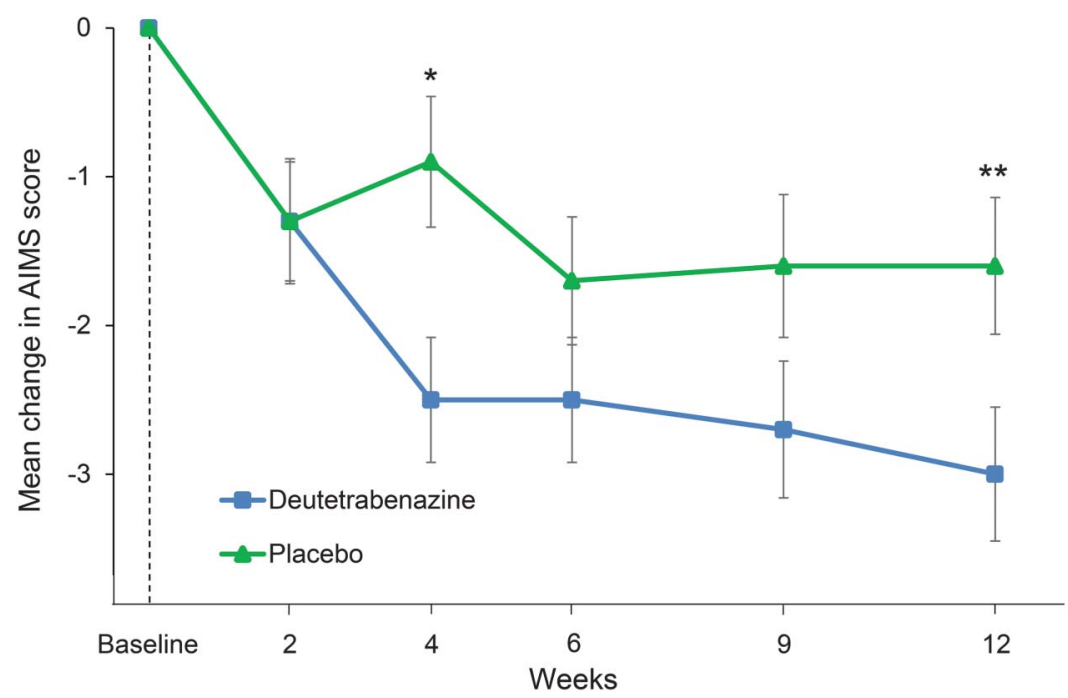

AIMS score was assessed over 12 weeks by central video rating in the mITT population based on the linear mixed model for repeated measurements. The mean change in AIMS score from baseline at weeks 2, 4, 6, 9, and 12 is depicted. Error bars represent standard error. AIMS $=$ Abnormal Involuntary Movement Scale; mITT $=$ modified intent to treat. $* p=0.007 . * * p=0.019$. the placebo group. Notably, the incidence of several AEs of interest in the deutetrabenazine group, such as depression/depressed mood and suicidal ideation, was similar to or lower than for placebo.

Serious AEs were reported by 3 patients (5.2\%) in the deutetrabenazine group and 5 patients $(8.5 \%)$ receiving placebo. Serious AEs in the deutetrabenazine group included community-acquired pneumonia, substance-induced manic episode, and exacerbation of schizophrenia ( $\mathrm{n}=1$ for each). Serious AEs in the placebo group included accidental heroin overdose, jaw fracture secondary to falling, jaw infection, pneumonia, and laryngeal hypertrophy $(\mathrm{n}=1$ for each). None were considered treatment related. There were no deaths during the study.

For the deutetrabenazine and placebo groups, there were relatively low rates of dose reductions, suspensions, and study withdrawals due to AEs, as presented in table 2.

Similar incidences of psychiatric AEs were observed in the overall deutetrabenazine group (20.7\%) and in the cohort of patients taking deutetrabenazine with antipsychotics (19.6\%), antidepressants (26.5\%), or anxiolytics (23.1\%). Deutetrabenazine treatment with concomitant antidepressants and anxiolytics was associated with similar rates of psychiatric AEs compared with placebo; however, there were more psychiatric AEs in patients treated with deutetrabenazine with antipsychotics compared with placebo $(19.6 \%$ vs $9.8 \%$ ). Nonetheless, the incidence of depressed mood,

Figure 3 Analysis of treatment effect for efficacy parameters

A. AIMS

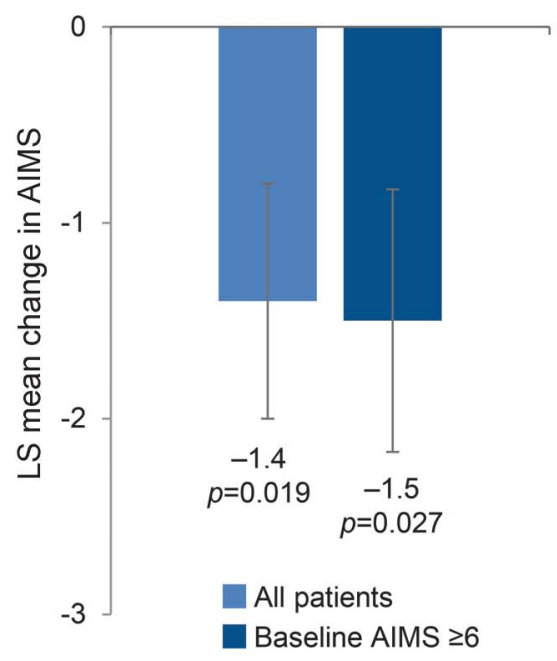

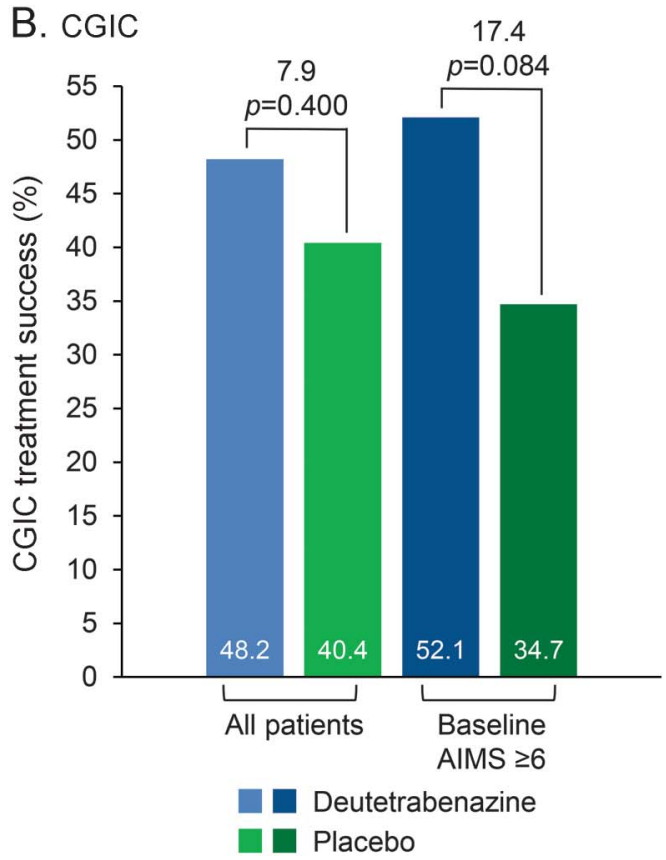

(A) Treatment difference (deutetrabenazine-placebo) of the LS mean change in AIMS score. (B) Proportion of patients who experience treatment success on the CGIC. Error bars for AIMS are standard error. AIMS = Abnormal Involuntary Movement Scale; CGIC = Clinical Global Impression of change; LS = least squares. 
Table 2 Patients who reported adverse events (AEs) in each treatment group

\begin{tabular}{|c|c|c|}
\hline & $\begin{array}{l}\text { Deutetrabenazine } \\
(\mathrm{n}=58), \mathrm{n}(\%)\end{array}$ & $\begin{array}{l}\text { Placebo } \\
(n=59), n(\%)\end{array}$ \\
\hline Any $A E$ & $41(70.7)$ & 36 (61.0) \\
\hline Serious AE & $3(5.2)$ & 5 (8.5) \\
\hline Treatment-related AEs & 28 (48.3) & 21 (35.6) \\
\hline$A E$ leading to dose reduction & $6(10.3)$ & $3(5.1)$ \\
\hline AE leading to dose suspension & $3(5.2)$ & 5 (8.5) \\
\hline$A E$ leading to discontinuation & $1(1.7)$ & 2 (3.4) \\
\hline \multicolumn{3}{|l|}{ AEs of interest } \\
\hline Depressed mood & $1(1.7)$ & $0(0.0)$ \\
\hline Depression & $0(0.0)$ & $1(1.7)$ \\
\hline Suicidal ideation & $0(0.0)$ & $1(1.7)$ \\
\hline \multicolumn{3}{|c|}{$\begin{array}{l}\text { AEs occurring in }>4 \% \text { of patients in either } \\
\text { treatment group }\end{array}$} \\
\hline Somnolence & 8 (13.8) & 6 (10.2) \\
\hline Fatigue & $4(6.9)$ & 5. (8.5) \\
\hline Insomnia & $4(6.9)$ & $1(1.7)$ \\
\hline Headache & $3(5.2)$ & 6 (10.2) \\
\hline Diarrhea & $3(5.2)$ & $3(5.1)$ \\
\hline Akathisia & $3(5.2)$ & $0(0.0)$ \\
\hline Anxiety & 2 (3.4) & $4(6.8)$ \\
\hline Dizziness & 2 (3.4) & $3(5.1)$ \\
\hline Dry mouth & 2 (3.4) & 6 (10.2) \\
\hline Upper respiratory tract infection & 2 (3.4) & $3(5.1)$ \\
\hline Rash & $1(1.7)$ & $3(5.1)$ \\
\hline Vomiting & $1(1.7)$ & $3(5.1)$ \\
\hline Deaths & 0 & 0 \\
\hline
\end{tabular}

depression, and suicidal ideation remained low and was similar to that of the overall deutetrabenazine group in patients receiving concomitant antidepressants.

Small reductions in parkinsonism severity, as measured by the Unified Parkinson's Disease Rating Scale motor assessment, were observed from baseline to week 12 in the deutetrabenazine (mean [SD] change -0.9 [8.09]) and placebo ( -3.8 [7.87]) arms. In addition, at week 12 , there were no safety signals detected on the Barnes Akathisia Rating Scale, HADS-Anxiety, HADS-Depression, Epworth Sleepiness Scale, or Montreal Cognitive Assessment. No deutetrabenazine-treated patient reported suicidal ideation or behavior on the Columbia Suicide Severity Rating Scale, whereas 3 patients (5.2\%) and 1 patient (1.7) in the placebo group reported suicidal ideation or behavior, respectively.

Finally, there were no meaningful differences in the QTcF interval prolongation between groups $(p=0.153)$. One placebo-treated patient exceeded a QTcF interval of 500 milliseconds.
DISCUSSION This study demonstrated that deutetrabenazine is efficacious for the treatment of abnormal movements in patients with TD, with a favorable safety and tolerability profile that enables the continued use of DRAs and antidepressants for the management of chronic psychiatric conditions. Almost all patients (98.3\%) enrolled in Aim to Reduce Movements in Tardive Dyskinesia (ARMTD) had an underlying psychiatric comorbidity for which they were receiving concomitant medications, making these results especially relevant to clinical practice for clinicians managing similar patients in a real-world setting.

In general, deutetrabenazine was well tolerated, as supported by the high study completion rate and infrequent dose reductions, dose suspensions, or withdrawals. These results are of particular importance because antipsychotic discontinuation or dose reduction is often not possible for patients with TD because of the high risk of psychotic exacerbation. ${ }^{9}$ Moreover, deutetrabenazine did not result in reports of depression or suicidal ideation and was associated with low rates of psychiatric AEs, including anxiety.

Because of possible differences between on-site and centralized video ratings of $T D$, natural variation in the severity of dyskinesia, and potential differences among patients' subjective feelings (e.g., more nervous during the initial video) at screening vs baseline, 20 enrolled patients had AIMS scores $<6$ as assessed by a central video rater at baseline, leaving 97 patients $(85.8 \%$ of the mITT population) with central video AIMS scores $\geq 6$ at both screening and baseline. Because this population is consistent with the intended study population, the key efficacy endpoints were assessed for this group to inform future study design. As with the mITT population, a significant improvement in AIMS score at week 12 was also observed with deutetrabenazine compared with placebo for this population. Deutetrabenazine provided greater clinical benefit, as evidenced by numeric improvement on CGIC, in patients with a central video AIMS score $\geq 6$ at screening and baseline, suggesting that patients with more severe TD may exhibit better clinical response.

The chronic, disabling nature of $\mathrm{TD}^{21,22}$ highlights the need for an effective treatment. The significant improvement observed in AIMS score was not fully reflected on CGIC and PGIC outcomes. This may be due to variable symptom appreciation by the clinician and the patient. Most patients in this trial were recruited and evaluated by psychiatrist investigators who may be less familiar with the motor nuances of TD compared with the management of behavioral disorders. Psychiatrists have not been 
consistently exposed to rigorous training on the scales used in the study. In addition, the dynamic nature of TD itself may limit the ability of these scales to fully capture meaningful change in involuntary movements. It is possible that tolerability issues could have dampened the CGIC and PGIC treatment effects. We believe this is unlikely because the active drug was very well tolerated.

There was, surprisingly, a notable placebo response among patients on the AIMS rating, which could have also affected the CGIC and PGIC ratings, despite the centralized video assessment. This may be attributed to the patients' perception or expectation of improvement due to the titration design and frequent clinic visits, compounded by the variability over time of TD, which is not often consistently manifested and is very susceptible to external factors such as stress, time of day, and intake of psychotropic medications. In addition, the positive findings of a related study in HD (First Time Use of SD-809 in Huntington Disease [First-HD]) were publically announced while this study was being conducted. ${ }^{19}$ The placebo effect on AIMS scores was less likely from the central raters because they were blinded to clinical information, concordance with another central rater was required, and all videos of each patient were viewed in the same sitting. Using central video raters reduces the potential for interrater variability ${ }^{23}$ or visit-specific factors, leading to more standardized measures.

There are few available treatment options for involuntary movements related to TD. The American Academy of Neurology guidelines do not conclusively recommend off-label use of tetrabenazine for the treatment of TD symptoms (Class III, Level C, Level U). ${ }^{8}$ This study provides Class I evidence that deutetrabenazine may serve as an efficacious and welltolerated treatment for abnormal movements in $\mathrm{TD}$, particularly in patients in whom disruption of treatment for underlying psychiatric conditions may not be an option.

\section{AUTHOR CONTRIBUTIONS}

Hubert H. Fernandez, Stewart A. Factor, Robert A. Hauser, Jooh Jimenez-Shahed, William G. Ondo, L. Fredrik Jarskog, Herbert Y. Meltzer, Scott W. Woods, Danny Bega, Mark S. LeDoux, David R. Shprecher, David Stamler, and Karen E. Anderson: significant content-related direction, data acquisition and analysis, contribution to the writing of the draft, and feedback on all relevant materials throughout the development of the manuscript. Charles Davis: significant content-related direction, contribution to the writing of the draft, and feedback on all relevant materials throughout the development of the manuscript. Mat D. Davis: significant content-related direction, statistical analysis, contribution to the writing of the draft, and feedback on all relevant materials throughout the development of the manuscript.

\section{ACKNOWLEDGMENT}

The authors thank the patients and site personnel involved with this study and Arianna Grove, $\mathrm{PhD}$ (Chameleon Communications International with funding from Teva Pharmaceutical Industries), for editorial assistance in the preparation of this report.

\section{STUDY FUNDING}

This study was funded by Teva Pharmaceutical Industries, Petach Tikva, Israel.

\section{DISCLOSURE}

H. Fernandez: honoraria: Prime Education Inc, Ohio State University, International Parkinson and Movement Disorders Society, Carling Communications, Medscape (as a speaker in Continuing Medical Education events), Biogen GE Healthcare, Lundbeck, Merz, Pfizer (as a consultant); research support: AbbVie, Acadia, Auspex/Teva, Biotie Therapeutics, Civitas, Kyowa/Prostrakan, Michael J. Fox Foundation, Movement Disorders Society, NIH/National Institute of Neurological Disorders and Stroke, Parkinson Study Group, Rhythm, Synosia; royalties: Demos Publishing; contractual services: AbbVie, Merz Pharmaceuticals, Auspex/ Teva, Xeomin Registry Study, Ipsen Pharmaceuticals; stipend: International Parkinson and Movement Disorders Society (for service as medical editor of the Movement Disorders Society website). S. Factor: honoraria: Neurocrine, Lundbeck, Auspex/Teva, Avanir, UCB, Sunovion, US WorldMeds; research support: Ipsen, Allergan, Medtronic, Auspex, US WorldMeds, Pharm-Olam, Cynapsus Therapeutics/Sunovion, Vaccinex, Solstice CHDI Foundation, Michael J. Fox Foundation, NIH; royalties: Demos, Blackwell Futura for textbooks, UpToDate. R. Hauser: consulting: Auspex/Teva, AbbVie, Acadia Pharmaceuticals, Acorda Therapeutics, Adamas Pharmaceuticals, Allergan Neuroscience, AstraZeneca, Biotie Therapies, Chelsea Therapeutics, Cynapsus Therapeutics, Impax Pharmaceuticals, Lundbeck, Michael J. Fox Foundation, Neurocrine Biosciences, Neuropore Therapies, Pfizer, Prexton, UCB Biosciences, and US WorldMeds. J. Jimenez-Shahed: research support: Acadia Pharmaceuticals, St. Jude Medical, Biotie Therapies, Solstice Neurosciences, Avid Radiopharmaceuticals, Michael J. Fox Foundation; consulting: Auspex/Teva, St. Jude Medical, Medtronic. W. Ondo: research support: Lundbeck, Tremor Research Group, Dystonia Coalition, Restless Legs Syndrome Foundation, Acorda; speaker's bureau: Teva, Impax, Lundbeck, UCB, US WorldMeds; consulting: Teva, Lundbeck, Acadia. L. Jarskog: research support: Auspex/Teva, Boehringer Ingelheim, Otsuka, NIH; consulting: Roche. H. Meltzer reports no disclosures relevant to the manuscript. S. Woods: research support: Teva, Pfizer; consulting: Boehringer Ingelheim, Nutria Health. D. Bega: research support: National Parkinson Foundation; speaker's bureau: Acadia Pharmaceuticals, Inc; consulting: Teva, Cynapsus, Acadia. M. LeDoux: speakers' bureau: Lundbeck, Acadia; consulting: Teva Neuroscience, US WorldMeds, Mayo Clinic, Starnes-Davis-Florie, Michael J. Fox Foundation, Benign Essential Blepharospasm Research Foundation, Dorothy/Daniel Gerwin Parkinson's Research Fund, Auspex, Teva, Acorda, CHDI; royalties: Elsevier (for editing Animal Models of Movement Disorders and Movement Disorders: Genetics and Models). D. Shprecher: consulting: Teva and Lundbeck; speaker's bureau: Teva and Lundbeck; research support: Arizona Alzheimer's Consortium, Adamas, Teva, Kyowa, Michael J. Fox Foundation, Neurocrine, NIH. C. Davis: consultant to Auspex Pharmaceuticals and Teva Pharmaceutical Industries. M. Davis: employee of Teva Pharmaceutical Industries. D. Stamler: employee of Teva Pharmaceutical Industries; personal fees from Auspex Pharmaceuticals outside the submitted work. K. Anderson: Scientific Advisor: North American study co-Principal Investigator for LEGATO-HD (Laquinimod Efficacy and Safety in a Global Trial of Huntington Disease), Global Principal Investigator for AIM-TD (Addressing Involuntary Movements in Tardive Dyskinesia), and Global co-Principal Investigator for ARM-TD. Site Principal Investigator for Pride-HD (Pridopidine Dose Evaluation in Huntington Disease), First-HD, ARC-HD (Alternatives for Reducing Chorea in Huntington Disease): Teva. Scientific Advisor, Site Principal Investigator for ENROLL-HD (A Prospective Registry Study in a Global Huntington Disease Cohort): CHDI Foundation. Scientific Advisor: Prana. Site Principal Investigator: Vaccinex. Consultant to the NeuroNext 105 study with Azevan. Go to Neurology.org for full disclosures.

Received November 3, 2016. Accepted in final form March 3, 2017. 


\section{REFERENCES}

1. Aquino $\mathrm{CCH}$, Lang $\mathrm{AE}$. Tardive dyskinesia syndromes: current concepts. Parkinsonism Relat Disord 2014;20 (suppl 1):S113-S117.

2. Tarsy D, Lungu C, Baldessarini RJ. Epidemiology of tardive dyskinesia before and during the era of modern antipsychotic drugs. In: William JW, Eduardo T, editors. Handbook of Clinical Neurology. Amsterdam, Netherlands: Elsevier; 2011:601-616.

3. Woods SW, Morgenstern H, Saksa JR, et al. Incidence of tardive dyskinesia with atypical and conventional antipsychotic medications: prospective cohort study. J Clin Psychiatry 2010; 71:463-474.

4. Samie MR, Dannenhoffer MA, Rozek S. Life-threatening tardive dyskinesia caused by metoclopramide. Mov Disord 1987;2:125-129.

5. Waln O, Jankovic J. An update on tardive dyskinesia: from phenomenology to treatment. Tremor Other Hyperkinetic Mov 2013;3:tre-03-161-4138-4131.

6. Jankelowitz SK. Treatment of neurolept-induced tardive dyskinesia. Neuropsychiatr Dis Treat 2013;9:1371-1380.

7. Bhidayasiri R, Boonyawairoj S. Spectrum of tardive syndromes: clinical recognition and management. Postgrad Med J 2011;87:132-141.

8. Bhidayasiri R, Fahn S, Weiner WJ, Gronseth GS, Sullivan KL, Zesiewicz TA. Evidence-based guideline: treatment of tardive syndromes. Neurology 2013;81:463-469.

9. Caroff SN, Hurford I, Lybrand J, Campbell EC. Movement disorders induced by antipsychotic drugs: implications of the CATIE schizophrenia trial. Neurol Clin 2011; 29:127-148.

10. Cloud LJ, Zutshi D, Factor SA. Tardive dyskinesia: therapeutic options for an increasingly common disorder. Neurotherapeutics 2014;11:166-176.

11. Zutshi D, Cloud LJ, Factor SA. Tardive syndromes are rarely reversible after discontinuing dopamine receptor blocking agents: experience from a University-based move- ment disorder clinic. Tremor Other Hyperkinetic Mov 2014;4:266.

12. Rana AQ, Chaudry ZM, Blanchet PJ. New and emerging treatments for symptomatic tardive dyskinesia. Drug Des Devel Ther 2013;7:1329-1340.

13. Huntington Study Group. Tetrabenazine as antichorea therapy in Huntington disease: a randomized controlled trial. Neurology 2006;66:366-372.

14. XENAZINE Prescribing Information. Deerfield, IL: Lundbeck; 2015.

15. Guay DR. Tetrabenazine, a monoamine-depleting drug used in the treatment of hyperkinetic movement disorders. Am J Geriatr Pharmacother 2010;8:331-373.

16. Shao L, Hewitt MC. The kinetic isotope effect in the search for deuterated drugs. Drug News Perspect 2010; 23:398-404.

17. Stamler D, Bradbury M, Brown F. The pharmacokinetics and safety of deuterated-tetrabenazine. Neurology 2013; 80:P07.210.

18. Timmins GS. Deuterated drugs: where are we now? Expert Opin Ther Patents 2014;24:1067-1075.

19. Huntington Study Group, Frank S, Testa CM, Stamler $\mathrm{D}$, et al. Effect of deutetrabenazine on chorea among patients with Huntington disease: a randomized clinical trial. JAMA 2016;316:40-50.

20. Epping EA, Kim JI, Craufurd D, et al. Longitudinal psychiatric symptoms in prodromal Huntington's disease: a decade of data. Am J Psychiatry 2016;173:184-192.

21. Casey DE. Tardive dyskinesia. West J Med 1990;153: 535-541.

22. Rittmannsberger $\mathrm{H}$. Ten year outcome of tardive dyskinesia during continuous treatment with first generation antipsychotics. Psychiatr Danub 2008;20:461-465.

23. Haidet KK, Tate J, Divirgilio-Thomas D, Kolanowski A, Happ MB. Methods to improve reliability of videorecorded behavioral data. Res Nurs Health 2009;32: 465-474.

\section{BrainPAC}

BrainPAC is the American Academy of Neurology's (AAN) federal political action committee.

- Since its inception, more than 3,600 AAN members have contributed $\$ 2,000,000$ to BrainPAC.

- BrainPAC contributed more than $\$ 600,000$ to individuals who ran for election in 2016, including several first-time candidates.

- During the 2016 congressional election, 92\% of candidates supported by BrainPAC won election to the US Congress.

BrainPAC supports both Democrats and Republicans who support issues important to the practice of neurology and the care of patients with neurologic conditions. US AAN members are invited to learn more at BrainPAC.org. 


\section{Neurology}

\section{Randomized controlled trial of deutetrabenazine for tardive dyskinesia: The ARM-TD study \\ Hubert H. Fernandez, Stewart A. Factor, Robert A. Hauser, et al.}

Neurology 2017;88;2003-2010 Published Online before print April 26, 2017

DOI 10.1212/WNL.0000000000003960

This information is current as of April 26, 2017

\begin{tabular}{|c|c|}
\hline $\begin{array}{l}\text { Updated Information \& } \\
\text { Services }\end{array}$ & $\begin{array}{l}\text { including high resolution figures, can be found at: } \\
\text { http://n.neurology.org/content/88/21/2003.full }\end{array}$ \\
\hline Supplementary Material & $\begin{array}{l}\text { Supplementary material can be found at: } \\
\text { http://n.neurology.org/content/suppl/2017/05/22/WNL.0000000000003 } \\
\text { 960.DC1 }\end{array}$ \\
\hline References & $\begin{array}{l}\text { This article cites } 21 \text { articles, } 3 \text { of which you can access for free at: } \\
\text { http://n.neurology.org/content/88/21/2003.full\#ref-list- } 1\end{array}$ \\
\hline Subspecialty Collections & $\begin{array}{l}\text { This article, along with others on similar topics, appears in the } \\
\text { following collection(s): } \\
\text { Class I } \\
\text { http://n.neurology.org/cgi/collection/class_1 } \\
\text { Clinical trials Randomized controlled (CONSORT agreement) } \\
\text { http://n.neurology.org/cgi/collection/clinical_trials_randomized_control } \\
\text { led_consort_agreement }\end{array}$ \\
\hline Permissions \& Licensing & $\begin{array}{l}\text { Information about reproducing this article in parts (figures,tables) or in } \\
\text { its entirety can be found online at: } \\
\text { http://www.neurology.org/about/about_the_journal\#permissions }\end{array}$ \\
\hline Reprints & $\begin{array}{l}\text { Information about ordering reprints can be found online: } \\
\mathrm{http} / / / \mathrm{n} \text {.neurology.org/subscribers/advertise }\end{array}$ \\
\hline
\end{tabular}

Neurology ${ }^{\circledR}$ is the official journal of the American Academy of Neurology. Published continuously since 1951, it is now a weekly with 48 issues per year. Copyright Copyright ( 2017 The Author(s). Published by Wolters Kluwer Health, Inc. on behalf of the American Academy of Neurology.. All rights reserved. Print ISSN: 0028-3878. Online ISSN: 1526-632X.

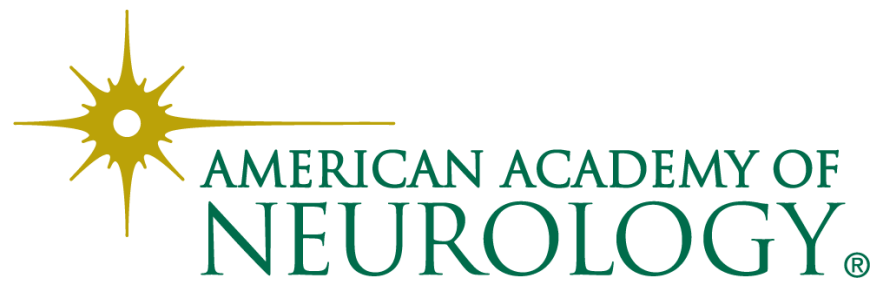

